\title{
Dealing with Aging and Multigeneration Workforce Topics at Top Global Companies: Evidence from Public Disclosure Information
}

\author{
H. I. Castellucci ${ }^{1}$, P. Arezes ${ }^{2,3}$, M. Lavallière ${ }^{3,4}$, N. Costa ${ }^{2,3}$, O. DaDalt ${ }^{3}$, J. F. Coughlin ${ }^{3}$ \\ ${ }^{1}$ Centro de Estudio del Trabajo y Factores Humanos, Universidad de Valparaíso, Valparaíso, Chile \\ ${ }^{2}$ ALGORITMI Centre, School of Engineering, University of Minho, 4800-058 Guimarães, Portugal \\ ${ }^{3}$ MIT AgeLab, United States \\ ${ }^{4}$ Centre de Recherche Universitaire Interdisciplinaire sur la Qualité et les Saines Habitudes de Vie, \\ Université du Québec à Chicoutimi. Canada \\ hector.castellucciuv.cl
}

\begin{abstract}
The way organizations deal with aging employees and the way they manage the existence of a multigenerational gap within the workforce falls well within the scope some public information reporting practices, such as corporate responsibility. The aim of this study is to ascertain the level and characteristics of reporting practices on aging and multigenerational workforce among the top $\mathbf{5 0}$ global companies. The analysis of the public information disclosure was carried out using a quantitative approach by applying a three-stage data collection procedure. It can be concluded that companies' information disclosure about aging workforce topics is markedly low and, accordingly, it appears at a low level of relevancy on their institutional websites structure/content, as well as in their public reports. The main finding pointed out to the fact that top global companies do not widely report the way they take actions to deal with aging and multigenerational workforce challenges.
\end{abstract}

Keywords - Public information, Disclosure, Ageing, Multigenerational, Older workers.

\section{INTRODUCTION}

Companies need to address an aging workforce and place themselves in a strong position to tackle the challenges this "new" reality may impose. Although aging is often presented as a risk factor from the human factors and ergonomics perspective [1], it could alternatively be seen as an advantage, as older employees tend to have greater experience, knowledge about the field, and significant "know-how."

Typically, measuring a specific company concern about a particular topic can be done by conducting on-site data collection or evaluation. However, if the focus is a set of companies that are spread worldwide, an alternative to on-site data collection is to use proxy indicator evidence from companies' public information disclosure in their most visible information sources (references to activity reports, social responsibility and/or sustainability reports, websites and references on the global world wide web) $[2,3]$.

Non-financial information released in corporate responsibility report has been coined in a variety of forms, such as 'social and environmental', 'corporate social responsibility' (CSR), 'sustainability', 'ethical', 'triplebottom-line' [4]. These terms reflect the effort, voluntary in principle, of a company releasing information towards its stakeholders and society as a whole $[5,6]$. The practice of disclosing non-financial information is not recent. The selection of topics to be included in this type of released information has also been a subject of discussion. Companies tend to report the information that is suggested by guidelines governing these practices, such as the Global Reporting Initiative [7].

Considering that sustainability reports should be centered on topics that are relevant for the organizations and the impact of their activities on society, it seems clear that the way organizations deal with aging employees and the way they manage the existence of a multigenerational gap within the workforce falls well within the scope of this type of report [8]. However, the main guidelines for the sustainability report, the GRI guidelines [7], suggest that organizations can report on several societal topics but does not mention any guidelines about reporting agingrelated topics. Because of the Internet's success and the global coverage of Internet users, companies have widely adopted it as their preferred communication channel [9]. Information is now regularly presented on websites within the Annual Reports, within Sustainability/Social Responsibility Reports and/or on other web pages, which may include press releases, speeches and presentations, case studies and ethical codes [10].

The aim of this study is to ascertain the level and characteristics of reporting practices on aging and multigenerational workforce among the top 50 global companies, as listed in the Fortune 500 top global 2015 ranking [11]. It is hypothesized that this level of reporting can be different across the different continents, as well as across the different activity sectors represented in the selected sample. Within this work, we want to highlight the importance of the aging workforce and create awareness of it among companies' managers, thus encouraging them to report such information in their public disclosure documents for all to see.

\section{METHODOLOGY}

This study consisted in conducting content analysis aiming at identifying and describing the public disclosure information on the topics of aging and multigenerational workforce among the world's largest companies. With this purpose, and as already adopted in previous studies (e.g., Holcomb et al. [12]; Grosser and Moon, [13]), three main data sources were considered: institutional websites, annual reports, and the Internet. As considered in other studies (e.g. Perrini,[14]), the rationale of the use of these data was that the public information disclosed through 
these platforms can be considered as a proxy indicator of the companies' concerns and actions about the analyzed topics.

According to Darus et al. [15], the increasing use of social networking and the sophistication of the companies' stakeholders have motivated corporations to use corporate websites to disseminate additional CSR information, thereby improving the accessibility of their public information and allowing them to engage with a more diverse group of stakeholders. Despite the high variability that can be found in terms of Internet reporting practices between companies, some authors, such as Marston and Polei [16] and Villiers et al. [17]), mentioned that certain factors, such as the company size, appear to be positively related to the level of online reporting. Since the current study only includes the largest companies in the world, it is likely that the company's size is not relevant when comparing the analyzed companies.

\section{A. Sample}

The sample of companies was obtained by reviewing the Fortune 500 Global Companies ranking [11] for the year 2015 and including the first 50 companies on the list. This list includes all the major world companies, and the ranking is organized by companies' reported revenues for the considered fiscal year.

The decision for assessing the top global multinational companies was due to the fact that, because of their size and global location, they have huge impacts on the ecologies of the economies in which they operate [18]. In addition, because these companies operate on a global scale, the general public has increasing awareness of these impacts, be they social, economic, or environmental.

The Fortune Top 50 included companies of three different continents, distributed by 16 countries, as presented in Table 1. Also, in terms of the activity sectors represented in the sample (Table 2), it is possible to note that the Finance and Energy sector are largely represented

\section{B. Data Collection}

The data were retrieved mainly from four different sources: i) the Fortune Top Global 500 ranking, ii) the institutional website of each company, iii) the companies' public reports, and from iv) the Internet. The information available from the Fortune ranking list was mainly about the company's general description and relevant figures,

TABLE I FORTUNE TOP 50 GLOBAL COMPANIES DISTRIBUTION BY CONTINENTS AND COUNTRIES

\begin{tabular}{lcc}
\hline Continent/Country & N & \% of sample \\
\hline Asia & 11 & $(32)$ \\
China & 3 & 22 \\
Japan & 1 & 6 \\
South Korea & 1 & 2 \\
Taiwan & & 2 \\
Europe & 4 & $(26)$ \\
France & 4 & 8 \\
Germany & 2 & 8 \\
Italy & 1 & 4 \\
Switzerland & 1 & 2 \\
The Netherlands & 1 & 2 \\
United Kingdom & & 2 \\
North America & & $(42)$ \\
USA & 21 & 42 \\
\hline
\end{tabular}

TABLE II SAMPLE DISTRIBUTION BY ACTIVITY SECTOR.

\begin{tabular}{lcc}
\hline Activity sector & N & \% of sample \\
\hline Automotive & 7 & 14 \\
Distribution & 9 & 18 \\
Electronics & 4 & 8 \\
Energy & 10 & 20 \\
Finance & 11 & 22 \\
Industrial Goods & 1 & 2 \\
Insurance & 4 & 8 \\
Telecommunications & 3 & 6 \\
Engineering \& Construction & 1 & 2 \\
\hline
\end{tabular}

such as the revenue and the number of employees. From the companies' institutional websites, most data involved analysis of the website for hits on the relevant topics. The public reports, also gathered from the institutional websites, were the third relevant data source.

The procedure for data collection for each of these sources was as follows:

i. Company data were collected directly from the Fortune 500 top global ranking available at the magazine's website;

ii. For each institutional website (English version), the procedure consisted of searching for references to the aging workforce and multigenerational workforce, hereafter only called "aging workforce topics" (AWT), within the website menu. If this data was found, the level of the website's menu at which it was found was also recorded. A 'menu' level of 0 meant the reference was found on the 'homepage' (or cover page) of the website, level 1, the first option of the menu, and so forth. Additionally, when found, the information AWT was also classified for the type of presented information (e.g., article, dedicated section, brief reference, etc.);

iii. Once on the website, a search was conducted for the public reports made available for each company. Those public reports are essentially of two types, an activity report (mostly with financial indicators designed for the information of the company stakeholders) and other type of reports that companies made available to the public, most commonly Corporate Social Responsibility (CSR) Reports or Sustainable Development Reports. Regarding the use of the public information reports, and as reported by Bouten et al.[2], previous studies on information disclosure had also focused on content analysis studies that addressed analysis of the disclosed CSR items (e.g., Jose \& Lee, [18]) or the measurement of the extent (number of words, sentences or pages) of CSR disclosure used to address the different CSR items (e.g., Campbell, [19]). In order to do so, each report was analyzed for the existence of any specific reference (chapter, separate point, etc.) to AWT. If found, the level of that section within the report was noted. As mentioned before, level 0 was considered to be the cover, with subsequent values increasing according to the level of sub-division of the topics. The following keywords were used to find references:

a. "Aging" OR "Ageing" OR "Older Workers" (and if the context of the sentence was related to the topic of aging);

b."Multigeneration" OR "Multi-Generation" OR

"Multigenerational" OR "Multi-Generational" OR

"Generation" OR "Generational" (and if the context of the

TABLE III TYPE OF AWT REFERENCES' ON INSTITUTIONAL WEBSITES.

\begin{tabular}{lc}
\hline \multicolumn{1}{c}{ Type of reference } & No. of Co. (out of 50) \\
\hline Equal employment opportunities & 11 \\
Brief reference to aging workforce & 10 \\
Article about aging & 4 \\
Employee's age structure & 2
\end{tabular}


sentence was related to the topic of aging).

iv. Google's search engine was used for the quantification of the number of hits collected on the internet using search strings related with the company, as follows:

a. Within the company web domain, the first search string was ("Ageing Workforce" OR "Aging Workforce " OR "Older Workers");

b.Within the company web domain, the second search string was ("Multi-Generation" OR "Multigeneration" OR "Multigenerational" OR "Multi-Generational") AND Workforce;

c. On the Internet, the last search string was ("Ageing Workforce" OR "Aging Workforce") OR "Older Workers") AND "CEO's name" AND "Company's name".

Once aggregated, this information was clustered by research question using some or all of the following variables: total no. of companies (by either continents or industry sector), $\%$ of companies referencing AWT, average 'menu' level where the references are found, and average number of references per company (of those who are reporting AWT).

The procedure for data collection, for all of the previously mentioned sources, consisted on the independent scanning by two of the authors, allowing them to identify the relevant information and defined the associated score or value. Disagreements between the two authors were referred to the others authors, leading to a deeper analysis and a decision was then made it.

\section{RESULTS}

\section{A. Institutional Websites}

Results obtained for the analysis of the aging topics showed that 27 out of the 50 top global companies have some sort of reference to the aging workforce topics (AWT) on their institutional webpages. Of these, most of the companies have included equal employment opportunities or a brief reference to these topics (Table 3 ).

Table 4 presents the percentage of companies, within each continent, that have any reference to AWT on their websites, as well as the corresponding level (in the website structure/index) in which they are reporting those topics.

When analyzing the results by continent, it can be seen that European companies have a much higher percentage of companies reporting AWT, with more than two third of the companies $(76.9 \%)$ reporting some sort of information regarding this issue. Also table 4 shows that Asian companies have the lowest percentage of aging information on the website. However, for those of whom who are reporting the information, the level of presentation within the website is equal to European websites.

With $57.1 \%$ of referencing these topics, North American companies present the information at a lower level than their European and Asian counterparts.

According to Cowen et al. [20], the industry category, or activity sector, of a company appears to have an influence in some types of social responsibility disclosure. For this reason, the analysis of the data was also extended
TABLE IV ANALYSIS OF REFERENCES TO AWT WITHIN THE INSTITUTIONAL WEBSITES BY CONTINENT

\begin{tabular}{lccc}
\hline \multicolumn{1}{c}{ Continent } & $\begin{array}{c}\text { Total no. of } \\
\text { Co. }\end{array}$ & $\begin{array}{c}\text { \% of Co. } \\
\text { referencing AWT }\end{array}$ & $\begin{array}{c}\text { AVG 'menu' } \\
\text { level* }\end{array}$ \\
\hline Asia & 16 & $25.0(\mathrm{n}=4)$ & 2.8 \\
Europe & 13 & $76.9(\mathrm{n}=10)$ & 2.8 \\
North America & 21 & $57.1(\mathrm{n}=12)$ & 3.3 \\
\hline
\end{tabular}

* The highest emphasis at the website corresponds to the level 0 , level 1 correspond to the 1 st level of the website menu. level 2 to the 2 nd. etc. to the differences between the activities sectors included in the studied sample. When analyzing data by activity sectors (Table 5), it is possible to identify that Telecommunications and Industrial Goods sectors presented the higher percentage of companies reporting AWT, with $100 \%$ coverage. However, it should be noted that there is only one company representing Industrial Goods in the Fortune's top 50 global companies. Although Energy and Finance sectors are not the most highly represented sectors (60 and $18.2 \%$, respectively), both present their references at a high level on their websites (2.3 and 2.5 , respectively).

Despite differences between continents and activity sectors, in general terms it can be concluded that companies' information disclosure about AWT is low and, accordingly, it appears at a low level of relevancy on their institutional websites structure/content. It also appears that European companies seem to be more aware of the aging challenge, based on their higher and wider reporting of the analyzed topics and, simultaneously, on the higher emphasis given to these same topics on the website architecture.

\section{B. Public Reports}

One of the most important and visible sources of a company's public information disclosure is its public report. As mentioned, the reports of the companies analyzed in this study were gathered directly from their websites.

For most of the companies, the available reports were regarding the fiscal year of 2016. However, it should be mentioned that one of the companies only had his 2014 report available on their website.

The considered main categories for the public reports were the Activity Report, which is mainly a financial report designed to fulfill legal obligations, while the Corporate (Social) Responsibility Report (including the Global Responsibility Report and Supplier Responsibility Report), and the Sustainable Development Report may be referred to as Corporate Citizenship [21].

TABLE V RESULTS OF THE ANALYSIS OF REFERENCES TO AWT WITHIN THE INSTITUTIONAL WEBSITES BY ACTIVITY SECTOR.

\begin{tabular}{lccc}
\hline \multicolumn{1}{c}{ Activity Sector } & $\begin{array}{c}\text { Total no. } \\
\text { of Co. }\end{array}$ & $\begin{array}{c}\text { \% of sector } \\
\text { referencing AWT }\end{array}$ & $\begin{array}{c}\text { AVG } \\
\text { 'menu } \\
\text { level }\end{array}$ \\
\hline Automotive & 7 & $42.9(\mathrm{n}=3)$ & 3,0 \\
Distribution & 9 & $55.6(\mathrm{n}=5)$ & 3,0 \\
Electronics & 4 & $75.0(\mathrm{n}=3)$ & 3,3 \\
Energy & 10 & $60.0(\mathrm{n}=6)$ & 2,3 \\
Finance & 11 & $18.2(\mathrm{n}=2)$ & 2,5 \\
Industrial Goods & 1 & $100(\mathrm{n}=1)$ & 4,0 \\
Insurance & 4 & $75.0(\mathrm{n}=3)$ & 4,0 \\
Telecommunications & 3 & $100.0(\mathrm{n}=3)$ & 3,0 \\
Eng. \& Construction & 1 & - & -
\end{tabular}


The final results of this analysis are presented in Table 6. This includes the percentage of companies from each continent who reported aging workforce references, as well as the level of those references and finally, the average number of references per company.

From the information presented in Table 6 , it is possible to see that, similar to the reported data for companies' webpages, the highest percentage of companies referencing AWT in reports was obtained by European companies (69.2\%). Asian and North American companies gave the most "visibility" to the topics, with an average level of 3.0 and 3.6, respectively.

In order to document the number of references found in analyzed reports, the total number of references retrieved were divided by the total number of companies in each analyzed category in order to obtain the average number of references per company. Table 6 shows that, also for this specific parameter, European companies are those who are referencing the AWT the most frequently within their reports, with a mean of 3.31 references per company. Conversely, Asian companies present the lowest number of references, with an average of 0.81 references per company. It is noteworthy to mention that North American companies are presenting averages similar to their Asian counterparts (1.10).

The analysis of the average number of references by sector shows that the Automotive, Energy and Electronics reference AWT the most, with over a half of the companies in each of these groups referencing AWT. Of these three sectors, Automotive and Electronics companies seem to report this information at the highest level (3.0). Interestingly enough, however, the sector that reported its references at the highest level overall was the Distribution sector, which reported references at an average level menu of 3.0, and yet only three out of the nine companies in this sector reported references. In the public reports analyzed for the current study, the Industrial Goods and Engineering \& Construction sectors did not make any references to the AWT.

It is also interesting to notice that sectors with the large amount of the companies, referencing aging-related topics presents the highest numbers of references per company (Energy and Automotive). The lowest number of references per company was obtained for the Finance sector, with an average of 0.36 references per company.

Aging references in the reports were also analyzed and classified regarding the type of actions mentioned by the company (Table 8). From that analysis, it was possible to see that, within the total of 22 references, 10 of them were referring only to their employees' age profile (46\%). Eight referred to a specific company policy, such as the consideration of the aging workforce when hiring or promoting people (36\%). Finally, only four of the

TABLE VI RESULTS OF THE ANALYSIS OF REFERENCES TO AWF IN PUBLIC REPORTS BY CONTINENT.

\begin{tabular}{lcccc}
\hline Continent & $\begin{array}{c}\text { Total no. of } \\
\text { Co. }\end{array}$ & $\begin{array}{c}\text { \% of Co. } \\
\text { referencing } \\
\text { AWT }\end{array}$ & $\begin{array}{c}\text { AVG } \\
\text { 'menu' } \\
\text { level }\end{array}$ & $\begin{array}{c}\text { AVG number } \\
\text { of references } \\
\text { per Co. }\end{array}$ \\
\hline Asia & 16 & $31.3(\mathrm{n}=5)$ & 3.0 & 0.81 \\
Europe & 13 & $69.2(\mathrm{n}=9)$ & 3.9 & 3.31 \\
North & 21 & $38.1(\mathrm{n}=8)$ & 3.6 & 1.10 \\
America & & & & \\
\hline
\end{tabular}

TABLE VII RESULTS OF THE ANALYSIS OF REFERENCES TO AWF IN PUBLIC REPORTS BY ACTIVITY SECTORS.

\begin{tabular}{lccc}
\hline \multicolumn{1}{c}{ Sector } & $\begin{array}{c}\text { \% of Co. } \\
\text { referencing } \\
\text { AWT }\end{array}$ & $\begin{array}{c}\text { AVG } \\
\text { 'menu' } \\
\text { level }\end{array}$ & $\begin{array}{c}\text { AVG number of } \\
\text { references per } \\
\text { Co. }\end{array}$ \\
\hline Automotive & $85.7(\mathrm{n}=6)$ & 3.5 & 2.29 \\
Distribution & $33.3(\mathrm{n}=3)$ & 3.0 & 1.33 \\
Electronics & $50.0(\mathrm{n}=2)$ & 3.5 & 0.75 \\
Energy & $60.0(\mathrm{n}=6)$ & 3.8 & 3.60 \\
Finance & $27.3(\mathrm{n}=3)$ & 3.7 & 0.36 \\
Industrial Goods & - & - & - \\
Insurance & $25.0(\mathrm{n}=1)$ & 4.0 & 0.5 \\
Telecommunications & $33.3(\mathrm{n}=1)$ & 4.0 & 2.0 \\
Eng \& Construction & - & - & - \\
\hline
\end{tabular}

references reported any specific intervention or action program related to aging $(18 \%)$.

\section{DISCUSSION}

An analysis of the sample profile yields some noteworthy patterns. It seems clear that European companies provide the greatest amount of public disclosure information about the AWT and their strategies for dealing with the multigenerational workforce in their reports and online. This is most likely due to the age structure (also known as the age pyramid) of these countries. Not only is the population of the continent very quickly, with those with more than 50 years old making up nearly one quarter of the workforce [22], but the recent economic crisis has also forced an increase in the European retirement age, an issue that will, no doubt, make this topic even more sensitive within European companies.

Another possible explanation for the differences found between continents can be related to the main objectives of the reporting practices. As suggested by Perrini [14], social and environmental reporting processes were initially created as internal communications, primarily to support the relationship between the company and trade unions, which is a key feature of the European workforce. Perrini also referred that the same trend does not seem to happen in Anglo-Saxon countries, where those disclosure practices are used more as a way of managing external pressure groups, and thus they may not wish to report sensitive topics, such as the aging of their employees.

Overall, the obtained results demonstrate that the amount of aging-related references at the companies' annual reports level is similar to the number of references observed on their web domains. This analysis also showed that the inclusion of the topics addressed in the CSR disclosure reports seems to depend on their position on the so-called 'materiality matrix', i.e., the measure by which companies gage which topics have the most significant impact for the external stakeholders, as well as for the internal stakeholders (or impact on the business); the higher the position on the materiality matrix, the more important they are to stakeholders, and thus, the more likely they are to be included in the reports.

Despite the valuable insights provided by these results, it is important to acknowledge that the present study does have some limitations. First, the search was carried out only using English words and in the English versions of the website/reports. This might have affected the obtained results, as companies might have reported the 
AWT in the website and/or reports but in their own language versions. However, the analyzed companies are ranked as the top 50 world companies, thus it is assumed that they are reporting their main public information in English, as this language is currently the gold standard for information disclosure.

Finally, it is important to mention that some future work have to be done updating the new Fortune Top 50 companies and comparing through different years.

\section{CONCLUSION}

This paper draws on the literature's assumption that corporate social disclosure can be considered as the most direct expression of companies' attitudes and behaviors regarding social responsibility and, in this particular case, regarding the topics of aging and multigenerational workforce as well.

Considering the study sample, it can be concluded that top global companies do not widely report the way they take actions to deal with aging and multigenerational workforce challenges. These topics are generally not addressed in their reports, and when they are, they are presented at lower level of importance in reports or on the Internet. There are a few companies that included information on these topics but, even amongst the highest "reporting" companies, this practice tends to be the exception rather than the rule. There are several possible reasons for this lack of aging workplace topics in companies' public materials and reports, but one main cause might simply be that such topics are not currently required by reporting guidelines Another possible cause, as mentioned before, is that companies do not see aging workforce-related topics as priorities or of special interest at the moment and thus do not publish information about them.

Aging and multigenerational workforce topics are undoubtedly important for the internal stakeholders, however, in order to be relevant enough for being included in companies' information disclosure they should be considered important for the external stakeholders as well.

\section{REFERENCES}

[1] Crawford JO, Graveling RA, Cowie HA, Dixon K. The health safety and health promotion needs of older workers. Occup Med., vol. 60, no. 3, pp. 184-192, 2010.

[2] Bouten L, Everaert P, Van Liedekerke L, De Moor L, Christiaens J. Corporate social responsibility reporting: A comprehensive picture? Account Forum, vol. 35, no. 3, pp. 187-204, 2011.

[3] Nekhili M, Nagati H, Chtioui T, Rebolledo C. Corporate social responsibility disclosure and market value: Family versus nonfamily firms. J Bus Res., vol. 77, pp. 41-52, 2017.

[4] Skouloudis A, Jones N, Malesios C, Evangelinos K. Trends and determinants of corporate non-financial disclosure in Greece. J Clean Prod., vol. 68, pp. 174-188, 2014.

[5] Liao P, Xia N, Wu C, Zhang X, Yeh J. Communicating the corporate social responsibility (CSR) of international contractors: Content analysis of CSR reporting. J Clean Prod vol. 156, pp. 327-336, 2017.

[6] Wuttichindanon S. Kasetsart Journal of Social Sciences Corporate social responsibility disclosure $d$ choices of report and its determinants: Empirical evidence from firms listed on the Stock Exchange of Thailand. Kasetsart $J$ Soc Sci., vol. 38, no. 2, pp. 156-162, 2017.

[7] GRI. Global Reporting Initiative. G4 Sustainability Reporting Guidelines - Reporting Principles and Standard Disclosures. Global Reporting Initiative: Amsterdam. 2013.

[8] Nazari JA, Hrazdil K, Mahmoudian F. Assessing social and environmental performance through narrative complexity in CSR reports. J Contemp Account Econ., vol. 13, no. 2, pp. 166-178, 2017.

[9] Snider J, Hill RP, Martin D. Corporate social responsibility in the 21 st century: a view from the world's most succesful firms. $J$ Bus Ethics., vol. 48, no. 2, pp. 175-187, 2003.

[10] Rowbottom N, Lymer A. Exploring the use of online corporate sustainability information. Account Forum., vol. 33, no. 2, pp. 176-186, 2009.

[11] Fortune. Fortune 2015 Top Global Companies Ranking. 2016.

[12] Holcomb JL, Upchurch RS, Okumus F. Corporate social responsibility: what are top hotel companies reporting? Int J Contemp Hosp Manag., vol. 19, no. 6, pp. 461-475, 2007.

[13] Grosser K, Moon J. Developments in company reporting on workplace gender equality?. A corporate social responsibility perspective. Account Forum., vol. 32, no. 3, pp. 179-198, 2008.

[14] Perrini F. Building a European portrait of corporate social responsibility reporting. Eur Manag J., vol. 23, no. 6, pp. 611-627, 2005.

[15] Darus F, Hamzah E, Yusoff H. CSR Web Reporting: The Influence of Ownership Structure and Mimetic Isomorphism. Procedia Econ Financ., vol. 7, pp. 236246, 2013.

[16] Marston C, Polei A. Corporate reporting on the Internet by German companies. Int J Account Inf Syst., vol. 5, no. 3, pp. 285-311, 2004.

[17] De Villiers C, Low M, Samkin G. The institutionalisation of mining company sustainability disclosures. J Clean Prod., vol. 84, no. 1, pp. 51-58, 2014.

[18] Jose A, Lee S. Environmental Reporting of Global Corporations: A Content Analysis Based on Website Disclosures. J Bus Ethics., vol. 72, no. 4, pp. 307-321, 2007.

[19] Campbell D. A longitudinal and cross-sectional analysis of environmental disclosure in UK companies - A research note. Br Account Rev., vol. 36, no. 1, pp. 107$117,2004$.

[20] Cowen SS, Ferreri LB, Parker LD. The impact of corporate characteristics on social responsibility disclosure: A typology and frequency-based analysis. Accounting, Organ Soc., vol. 12, no. 2, pp. 111-122, 1987.

[21] De George RT. Business Ethics. Dorling Kindersley, licensees of Pearson Education in South Asia.; 2011. 534 p.

[22] Vendramin P, Valenduc G. Occupations and ageing at work: An analysis of the findings of the fifth European Working Conditions Survey. Eur Trade Union Inst Work Pap. 2012. 